\title{
Morphometric analysis of the vertebral level of origin of the coeliac trunk and its length
}

\author{
Vinitha $\mathbf{G}^{1, *}$, Pampanagouda ${ }^{2}$ \\ ${ }^{1}$ Assistant Professor, ${ }^{2}$ Surgical Oncologist, Dept. of Anatomy, Bangalore Medical College and Research Institute, \\ Bengaluru, India
}

*Corresponding Author:

Email: drvinithagang@gmail.com

\begin{abstract}
Introduction: The advent of minimal invasive surgery, robotic surgeries, radiological procedures and increased frequency of laparoscopic surgeries has made the clinicians to have a good knowledge of asymptomatic vascular anatomic variations.

Aim: In this study coeliac trunk (CT) length and its vertebral level of origin was noted and analyzed.

Materials and Methods: 45 cadavers (32 male, 13 female) in the department of Anatomy, Bangalore Medical College and Research institute were dissected during 2014-17, data collected analyzed and compared.

Results: The average length of CT was $1.5 \mathrm{cms}$ ranging between $0.3 \mathrm{~cm}$ to $2.7 \mathrm{~cm} .6$ cadavers measured $<1 \mathrm{~cm}, 19$ between 1.1 to $1.5 \mathrm{~cm}, 16$ between 1.6 to $2 \mathrm{~cm}, 3$ between 2.1 to $2.5 \mathrm{~cm}$ and only 1 measured $>2.6 \mathrm{~cm}$. The level of origin of CT was $26(58 \%)$ cadavers at lower border of T12, 13(29\%) cadavers between T12 and L1 and only $6(13 \%)$ of them at upper border of L1.

Conclusion: Morphometric knowledge of CT with its subtypes and variants has become necessary for surgeons and radiologists to do proper preoperative planning in transplantation and tumor resections.
\end{abstract}

Keywords: Coeliac trunk length, Coeliac trunk origin, Coeliac trunk variations, Computed tomography, Branches.

Received: $01^{\text {st }}$ December, 2017

\section{Introduction}

The coeliac trunk (CT) is one of the most well documented and researched surgically significant abdominal artery supplying most of the supracolic organs. It is the first anterior branch of the abdominal aorta. It measures approximately about $1.25 \mathrm{~cm}$ in length. It originates just below the aortic hiatus (lower border of T12) and passes horizontally forward, slightly above the pancreas and splenic vein, dividing into left gastric, splenic and common hepatic arteries. ${ }^{1}$

Aurthur Keith has stressed the fact that anatomic variations are rampant in biliary region. These anatomical variations sometimes make the clinicians err in their diagnosis, and impair the outcome of patient management. Surgeons and interventional radiologists should have the complete knowledge of these anatomical variations of $\mathrm{CT}$ for accurate interpretation of the diseases, in diagnostic imaging, and deciding the optimal elective procedure for better results.

Hepatic arterial chemotherapeutic infusion for unresectable hepatic malignancies and liver transplantations require correct preoperative vascular planning for anastomosing the arteries properly in the supracolic region, and is based on detailed knowledge of CT and its variations.
Laparoscopic procedures are inherently associated with increased risk of vascular injuries. These iatrogenic vascular complications can be avoided by a thorough knowledge of variant anatomy of CT. Vascular variations which are usually asymptomatic have to be kept in mind while planning for chemoembolization and trans catheter therapy of pancreatic, hepatic tumors and coeliacography.

Several studies are available on CT branches, but not much emphasized on its length and vertebral level of origin. An attempt has been made in this study to record these data, correlate and analyze. This study can be done on both cadavers and on computerized tomography imaging but in our study it has been done on cadavers.

\section{Materials and Methods}

The study material comprised of 45 well embalmed human cadavers which were allotted for routine dissection in the Department of Anatomy at Bangalore Medical College and Research Institute during a period of 4 years. Out of these 32 were males and 13 were females, and aged between 40 to 60 years. Dissection was done according to the guidelines given in Cunningham's manual. The peritoneal cavity was opened, coeliac trunk identified at superior 
border of pancreas and all its branches were skeletonized. CT was traced up to the abdominal aorta, and its length measured from abdominal aorta to its first branch with the help of thread and scale. Vertebral level of origin of CT noted. All the data obtained was recorded, analyzed and compared with the previous studies in the literature.

\section{Results}

A total of 45 CTs length from origin to $1^{\text {st }}$ branch (excluding additional branch) were measured and noted. The vertebral level of orgin of CT was also noted. Fig. 1 shows length of coeliac trunk.

Length of Coeliac Trunk: On an average (mean) the length was $1.5 \mathrm{~cm}$, shortest being 0.3 $\mathrm{cm}$ and longest being 2.7 with standard deviation of 0.07 . Median was $1.47 \mathrm{~cm}$. In the observed values Mean and Median are almost same showing normal distribution. Maximum number of cadavers had the length ranging from 1.1 to $1.5 \mathrm{~cm}$ seen in $19(42.2 \%)$ cadavers. This was followed by 1.6 to $2 \mathrm{~cm}$ observed in $16(35.6 \%)$ and subsequently $<1 \mathrm{~cm}$ seen in $6(13.3 \%)$ specimens. In $3(6.7 \%)$ of the cadavers the length ranged from 2.1 to $2.5 \mathrm{~cm}$. In only one cadaver $(2.2 \%)$ length was more than $2.6 \mathrm{~cm}$. Table 1 shows the range distribution of length of coeliac trunk.

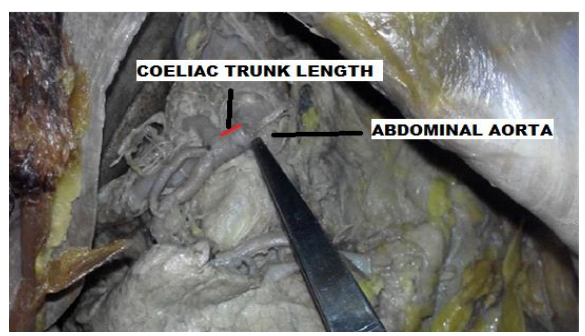

Fig. 1: Coeliac trunk length

Table 1: Range distribution of length of the coeliac trunk

\begin{tabular}{|l|c|c|}
\hline Range of length in cms & Number of cadavers & Percentage \\
\hline$<1$ & 6 & 13.3 \\
\hline 1.1 to 1.5 & 19 & 42.2 \\
\hline 1.6 to 2 & 16 & 35.6 \\
\hline 2.1 to 2.5 & 3 & 6.7 \\
\hline$>2.6$ & 1 & 2.2 \\
\hline
\end{tabular}

Vertebral Level: In the present study, CT was originating at the level of lower border of T12 in 26 $(58 \%)$ of cadavers, between T12 and L1 in 13(29\%) of cadavers, and in $6(13 \%)$ of them it arose from upper border of L1. Table 2 shows the distribution of vertebral level of origin of coeliac trunk.

Table 2: Vertebral level of origin of coeliac trunk

\begin{tabular}{|l|c|c|}
\hline \multicolumn{1}{|c|}{ Vertebral level } & Number of cadavers & Percentage \\
\hline T12 & 13 & 29 \\
\hline T12-L1 & 26 & 58 \\
\hline L1 & 6 & 13 \\
\hline
\end{tabular}

\section{Discussion}

In the literature it is observed that $\mathrm{CT}$ length has been measured from origin to $1^{\text {st }}$ branch, origin to last branch, and distance between them. In our study it was measured from origin to first branch excluding additional branches.

The mean length of $1.5 \mathrm{~cm}$ and the length range distribution from $0.3 \mathrm{~cm}$ to $2.7 \mathrm{~cm}$ noted in our study is similar to the study done by pushpalatha et al, ${ }^{2}$ Tiwari et al ${ }^{3}$ and Gosai et al. ${ }^{4}$ This study has been compared with previous similar studies and the findings tabulated in table 3 with respect to length and table 4 with respect to vertebral level of origin of coeliac trunk.

Table 3: Comparison of length measured in our study with similar previous studies

\begin{tabular}{|c|c|c|}
\hline Author & Mean length in cm (SD) & Range in cms \\
\hline Sachin et al ${ }^{10}$ & $1.9(6.3)$ & $0-4$ \\
\hline Severino varies et $\mathrm{al}^{8}$ & $2.33(0.65)$ & $1-4.1$ \\
\hline Dionysios venieratos et $\mathrm{al}^{5}$ & $2.8(0.8)$ & - \\
\hline Prakash gosai et $\mathrm{al}^{4}$ & $1.18(0.27)$ & $0.4-2$ \\
\hline
\end{tabular}




\begin{tabular}{|l|c|c|}
\hline${\text { Pushpalatha et } \mathrm{al}^{2}}^{2}$ & - & $0.4-2.9$ \\
\hline Suman tiwari et $\mathrm{al}^{3}$ & $1.2(0.56)$ & - \\
\hline Present study & $1.05(0.07)$ & $0.3-2.7$ \\
\hline
\end{tabular}

Table 4: Comparison of level of origin in present study with similar previous studies

\begin{tabular}{|l|c|c|c|c|c|c|}
\hline $\begin{array}{c}\text { Vertebral } \\
\text { level }\end{array}$ & $\begin{array}{c}\text { Pushpalatha } \\
\text { et al }\end{array}$ & $\begin{array}{c}\text { Lakshana et } \\
\mathbf{a l}^{\mathbf{1 1}}\end{array}$ & $\begin{array}{c}\text { Wadhwa et } \\
\mathbf{a l}^{\mathbf{7}}\end{array}$ & $\begin{array}{c}\text { Deena et } \\
\mathbf{a l}^{\mathbf{1 2}}\end{array}$ & $\begin{array}{c}\text { Hamzah et } \\
\mathbf{a l}^{\mathbf{1 3}}\end{array}$ & Present \\
\hline T11-12 & & & & & $12 \%$ & \\
\hline T12 & $66 \%$ & $10.7 \%$ & - & $6 \%$ & $40 \%$ & $29 \%$ \\
\hline T12-L1 & $4 \%$ & $70.7 \%$ & $73.3 \%$ & $70 \%$ & $32 \%$ & $58 \%$ \\
\hline L1 & $24 \%$ & $18.6 \%$ & $26.6 \%$ & $24 \%$ & $12 \%$ & $13 \%$ \\
\hline L1-2 & & & & $4 \%$ & \\
\hline
\end{tabular}

Tiwari et al has observed significant association of CT length and branching pattern, and showed increased association of varying branch pattern with short CT length. ${ }^{3}$ In our study such association was not appreciated as only 2 short CT lengths had tetrapod branching pattern and the remaining branching variations were observed in median to long length of CT.

Venieratos et al appreciated the longer mean length of CT in false tripod branching group than true tripod group, but it was not statistically significant. ${ }^{5}$ Similar observation was made in our study where false tripod branching group had longer length of CT. In our study majority of the cadavers had false tripod pattern of CT branching.

Cavdar et al noted the association of longer CT with varied origin of the left gastric artery (LGA) from hepatic artery, splenic artery or from the aorta. ${ }^{6}$ Such an association was not seen in the longest $\mathrm{CT}$ documented where LGA originated from CT itself. Wadhwa et al observed this association in his study where 2 long CT in his study $(2 \mathrm{cms} \& 2.1 \mathrm{cms})$ LGA arose from the splenic artery. ${ }^{7}$ No such observations were made in this study as the longest CT $(2.7 \mathrm{cms})$ had LGA origin from CT itself.

Severino et al observed a positive correlation between CT length and diameter, and that is increased CT length associated with increased CT diameter. Regional variation in $\mathrm{CT}$ length has been observed when compared in Greek and Brazilian studies, but diameter being the similar. ${ }^{8}$ Silveira et al suggested doing more studies on CT length and diameter based on above observations as they are useful for vascular surgeons and to prevent iatrogenic injuries. ${ }^{9}$ Unfortunately to analyze further, CT diameter has not been measured in our study.

Level of origin of CT in our study showed concentrating more towards $\mathrm{T} 12$ and between T12-L1 (87\%) which is similar to Lakshana et $\mathrm{al}^{11}$ study.
While doing lymphnode dissection in cancer of pancreas, hepatobiliary tree and stomach the variation in level of origin should be borne in mind to prevent injury of adjacent vessels.

Vertebral bodies are referred for doing abdominal angiography by interventional radiologists who select the vessel for injecting the dye without visualizing the vessel, and they have to know the anatomic variations to prevent the errors. ${ }^{8}$

We need to be cautious when the origin is at L1, as simultaneously superior mesenteric artery and renal arteries also arise at the same level.

Patient presenting with severe post prandial epigastric pain, nausea and vomiting, we should rule out coeliac axis compression syndrome due to high coeliac trunk origin, or probable congenital extended coeliac trunk. ${ }^{3}$

Factors for anatomical variant CT are developmental changes in visceral organs, midgut rotation, physiological hernia, haemodynamic changes in abdominal viscera and leftward migration of spleen. ${ }^{3}$

Professionals who design and develop stents and surgeons who place the stents should have a clear knowledge of the length and diameter of the vessels and including its anatomic variation. This has become necessary for better preoperative planning in abdominal angioplasty, catheterization and minimal invasive surgery.

\section{Conclusion}

Morphometric knowledge of coeliac trunk is useful for surgeons and radiologists for assisting them in better patient management in procedures like lymphadenectomy around hepatosplenomesentric trunk, aortic reimplantation, interpretation of diagnostic imaging, abdominal angioplasty, tumor resection, minimal invasive laparoscopic and robotic surgeries by avoiding iatrogenic vascular injuries. Further studies are required to know the diameter of coeliac trunk and its branches for 
better outcomes in the above mentioned clinical conditions.

\section{References}

1. Bannister L H et al, Gray's Anatomy, $38^{\text {th }}$ ed London, Churchill Livingstone 1995:1548-1553.

2. Pushpalatha K, Deepa Bhat, NM Shamsundar. "A Study of Anatomical Variations in the origin, length and branches of coeliac trunk and its surgical significance" International Journal of Anatomy and Research (2016) 6(1),1781-8.

3. Tiwari S, K. Jeyanthi. "Study of Coeliac trunk length and its branching pattern" IOSR Journal of Dental and Medical Sciences (2013) 8(6), 60-5.

4. Gosai P, Sanjay K, Jitendra Patil et al. "A Study of Morphology of Coeliac Trunk in 100 Cadavers" International Journal of Medical Science and Public Health (2013) 2(4),927-30.

5. Venieratos D, Panagouli E et al. "A Morphometric study of the coeliac trunk and review of literature" Clinical Anatomy (2012) 26(6), 741-50.

6. Cavdar S, Sehirli U, Pekin B. "Celiacomesentric trunk" Clinical Anatomy (1997) 10, 231-4.

7. Wadhwa A, Soni S. "A Composite study of coeliac trunk in 30 adult human cadacvers - its clinical implications" Global journal of medical research (2011) 11(1),35-8.

8. Severino A, Henrique A, Carlos F et al.

"Anatomical variations of the coeliac trunk and hepatic arterial system: an analysis using multidetector computed tomography angiography" Radiologia Brasileira (2015) 48(6),358-62.

9. Silveira LA, Silveira FBC, Fazan VPS. “Arterial diameter of the coeliac trunk and its branches Anatomical Study" Acta Cir Bras (2009) 24, 43-7.

10. Yadav SP, Sinha RS, Tushar Patil. "Study of variations of coeliac trunk in western Maharashtra population" International Journal of current Research and Review (2014) 6(23),31-8.

11. Selvaraj L, Sundaramurthi I. "Study of normal branching pattern of the coeliac trunk and its variations using CT angiography" Journal of Clinical and Diagnostic Research (2015) 9(9),1-4.

12. Deena K, Ashalatha D. "Variations in Branching pattern of coeliac trunk" IOSR Journal of Dental and Medical Sciences (2015) 14(11), 54-8.

13. Hamzah MH, Deepa SG. "A Study of Morphometric variations of Coeliac Trunk using Computed Tomographic Angiography" Indian Journal of Clinical Anatomy and Physiology (2016) 3(1), 8690 . 